Original Research Paper

\title{
Determinants of Sicilian Wine Consumption: Evidence from a Binary Response Model
}

\author{
${ }^{1}$ Francesco Caracciolo, ${ }^{2}$ Giuseppe Di Vita, ${ }^{3}$ Maurizio Lanfranchi and ${ }^{2}$ Mario D'Amico \\ ${ }^{1}$ Department of Agricultural Sciences, \\ Agricultural Economics and Policy Group, University of Naples Federico II, Naples Italy \\ ${ }^{2}$ Department of Agri-Food and Environmental Systems Management (DiGeSA), University of Catania, Italy \\ ${ }^{3}$ Department of Economics, Business, \\ Environment and Quantitative Methods (SEAM), University of Messina, Italy
}

Article history

Received: 30-06-2015

Revised: 26-08-2015

Accepted: 27-10-2015

Corresponding Author:

Mario D'Amico

Department of Agri-Food and

Environmental Systems

Management (DiGeSA),

University of Catania, Italy

Email: mario.damico@unict.it

\begin{abstract}
The growing importance of Sicilian wines in the Italian market provides the context in which this paper is set. This study presents the results of a recent survey on Sicilian wine consumption in Italy. By means of a binary response model, this paper evaluates the main determinants (demographic profile, preference and attitudes) that influence Italian consumers' preferences for Sicilian wines. The estimates, based on the stated preference of 953 Italian wine consumers, emphasize that income and habits to purchase at wine shops and the habit to drink between meals significantly influence the willingness to consume Sicilian wines. Furthermore the sample propensity to consume the Sicilian wine increases for white wines and when the consumption takes placed in public spaces.
\end{abstract}

Keywords: Regional Wine, Stated Preference, Willingness to Consume

\section{Introduction}

The Italian wine industry has experienced a strong renewal that has involved the structure, the organization and the management of grapevine farms (D'Amico et al., 2013; Di Vita et al., 2014a; Galati et al., 2014). This trend has gradually involved the Sicilian wine system, which has gradually approached the issues linked to the development of "quality vine growing" as a strategic factor of differentiation through the widespread of Products of Designated Origin (PDO), Protected Geographic Indication Products (PGI) and bottled wine productions that has contributed to the increasing of the Sicilian wine agribusiness (Crescimanno et al., 2014; Tudisca et al., 2014). Furthermore there has been a growing process in Sicilian wine appreciation in the extra-regional markets as recently reported in several studies (Roma et al., 2013). The success of Sicilian wines is in large part due to the several efforts put by manufacturers into obtaining quality products, both in the production and marketing phases (Di Vita et al., $2013 b ; 2013 c)$. The growing importance of Sicilian wines in the domestic and foreign market and the favourable forecasting of Sicilian wines to increase the market share in Italy (Caniglia et al., 2008) have led us to consider them as an interesting case study to identify the determinants in choosing the Sicilian wines.
In recent years the increasing demand of the consumers for quality wines and regional brand in the international and domestic markets has been a relevant discussion topic among researchers (Orth et al., 2005; Bruwer and Johnson, 2010; Onofri et al., 2015; Dal Bianco et al., 2015). At the same time a significant interest of Italian consumers towards "certified" as well organic products, has been observed (Crescimanno et al., 2002; Di Vita et al., 2013a; Cembalo et al., 2014; Di Vita et al., 2014b). Within this context, studies of Sicilian wine consumption are fairly limited and they are mainly circumscribed to specific protected designation of origin or geographical defined areas (Caniglia et al., 2008; Caracciolo et al., 2013; Lanfranchi et al., 2014a). There exists a certain paucity of studies on Sicilian wine consumption in the domestic market.

With the purpose of gathering information on the potential interest in bottled wines, this paper-through an econometric analysis using the stated preferences of consumers-presents the results of a recent survey on quality Sicilian wine consumption in Italy. The aim of the present study is to investigate the effect of socioeconomic factors, individual attitudes and preference of consumers on the probability of buying Sicilian quality wine, identifying the profile of the ideal Sicilian wine consumer. 
This paper is organized in four different sections. The first one describes the data collection process, the survey design, the methodology adopted in the study and introduces the econometric model and the estimation strategy. The second part shows the results of the survey discussing the main findings and the more relevant implication. The third section illustrates the main results of the research, while the last section concludes the paper.

\section{Materials and Methods}

Data

The data employed in this study consists of a crosssectional wine consumption survey collected in 2011. A random sample of Italian consumers was interviewed face-to-face in four metropolitan cities and a questionnaire completed: It is worth noting that stores located in metropolitan cities provide access to a wide variety of different wines (including extra-regional). The four metropolitan cities were selected to provide coverage of north, central and south areas: Milan (Lombardy), Rome (Lazio), Catania and Palermo (Sicily). More specifically, the questionnaire investigated consumer attitudes and preferences towards the Sicilian wine. The survey involved a total of 1,200 consumers. However, after dropping observations for which there were inconsistencies or missing data, a total of 953 responses (slightly less than $80 \%$ of the starting sample) were used in the empirical analysis. The collected information included: (a) respondents' characteristics (e.g., sociodemographic characteristics, level of education, household income); (b) respondents' general attitudes towards wine consumption (type of wine purchased, description of the consumption modalities, including main factors that influence the choice and the consumption of wine, styles and places of purchase and consumption; (c) respondents' intention to purchase Sicilian wine (including consumer knowledge of Sicilian geographical indications and protected designation of origin).

\section{Methodology}

This section presents the methodological approach aiming to analyze the consumption and purchase determinants of Sicilian quality wines. The hypothesis which is the basis of the present research is that respondents' willingness to consume Sicilian wine can be considered as a function of the following explanatory variables:

- Respondents socio-demographic characteristics

- A set of variables expressing the respondents preferences towards the various attributes of the wine

- A set of variables reporting the respondents attitude towards wine consumption
- A set of variables indicating the preferences of the respondents for the different channels of purchase

The selection of the explanatory variables follows previous studies of consumers preferences for food products and for wine specifically (Verneau et al., 2014; Cembalo et al., 2014; Caracciolo et al., 2015; Onofri et al., 2015).

The methodology will statistically assess the influence of each of the above reported variables on the respondents "willingness" or "likelihood" to consume Sicilian bottled wine. Analytically, the statistical model used for the analysis is a binary response model. This class of models is widely used in social sciences and in agricultural and food economics in particular for analyzing consumers choice behavior (Train, 2009; Verneau et al., 2014; Onofri et al., 2015). In this particular model the probability of an event (e.g., consumption of Sicilian wine) is a linear function of the explanatory variables. The relationship subjected to empirical investigation can generally be expressed as:

$$
\begin{aligned}
& \pi_{i}=\operatorname{Prob}\left(Y_{i}=1\right)=\operatorname{Prob}\left(Y_{i}^{*}>0\right) \\
& =\operatorname{Prob}\left(-\varepsilon_{i}<\alpha+\delta K_{i}+\beta X_{i}+\gamma Z_{i}+\tau W_{i}\right) \\
& =\Phi\left(\alpha+\delta K_{i}+\beta X_{i}+\gamma Z_{i}+\tau W_{i}\right)
\end{aligned}
$$

Where:

$\pi_{i}=$ Identifies the probability that the $i$-th respondent consumes a bottle of Sicilian wine

$Y_{i}^{*}=$ The non observable latent variable on which the statistical relationship with the explanatory variables is estimated

$Y_{i}=$ The observed binary variable that indicates the consumption $\left(Y_{i}=1\right)$ or the non consumption $\left(Y_{i}=\right.$ $0)$ of the Sicilian wine for the $i$-th respondent: This variable is associated to the latent variable according to the following rule $Y_{i}=1$ if $Y_{i}^{*}>0$ and $Y_{i}=0$ if $Y_{i}^{*} \leq 0$

$K_{i}=$ Identifies the vector comprising the sociodemographic characteristics of the $i$-th respondent

$X_{i}=$ Identifies the vector including the variables accounting for the preferences of the $i$-th respondent towards different attributes of the wine

$Z_{i}=$ Identifies the vector reporting the variables concerning the $i$-th respondent attitudes towards wine consumption

$W_{i}=$ Identifies the vector containing the variables expressing the preferences of the $i$-th respondent for the different channels of wine marketing and distribution

$\Phi=$ The cumulative distribution function of a standard normal distribution

$\varepsilon_{i}=$ The error term, independent and identically distributed (i.i.d.) according to a standardized normal distribution $\varepsilon_{i} \sim \mathrm{N}(0,1)$ 
Table 1. Description and summary statistics of the explanatory variables

\begin{tabular}{|c|c|c|c|c|c|}
\hline Variable & Description & Mean & Std.dev & Min & Max \\
\hline \multicolumn{6}{|c|}{ K: Socio Demographic characteristics } \\
\hline Age & Age of the respondent & 48.008 & 12.669 & 18 & 82 \\
\hline \multirow[t]{2}{*}{ Degree of education } & 0 no education; 1 primary; 2 secondary; & & & & \\
\hline & 3 High school; 4 Bachelor & 3.404 & 0.683 & 0 & 4 \\
\hline \multirow[t]{2}{*}{ Income } & Household income: 0 max 15,000 euros; & & & & \\
\hline & $\begin{array}{l}1 \text { between } 15,000 \text { and } 30,000 \text { euros; } 2 \text { between } 30,000 \\
\text { and } 50.000 \text { euro; } 3 \text { more than } 50,000 \text { euros }\end{array}$ & 1.356 & 0.811 & 0 & 3 \\
\hline Gender & 0 male; 1 female & 0.274 & 0.446 & 0 & 1 \\
\hline South & 1 lives in south Italy, 0 elsewhere & 0.498 & 0.500 & 0 & 1 \\
\hline \multicolumn{6}{|c|}{ Z: Attitudes towards wine consumption } \\
\hline Between meals & $\begin{array}{l}\text { Importance of consuming wine between meals } \\
1 \text { not important, } 3 \text { very important }\end{array}$ & 1.428 & 0.664 & 1 & 3 \\
\hline \multirow[t]{2}{*}{ Restaurant } & Relevance of wine consumption place, restaurant: & & & & \\
\hline & 1 not relevant, 6 very relevant & 3.336 & 1.410 & 1 & 6 \\
\hline \multirow[t]{2}{*}{ Advertising } & Relevance of advertising in encouraging purchases: & & & & \\
\hline & 1 not relevant, 6 very relevant & 2.454 & 1.305 & 1 & 6 \\
\hline Guides & 1 if wine guides are used, 0 otherwise & 0.243 & 0.429 & 0 & 1 \\
\hline \multicolumn{6}{|c|}{$X:$ Preferences towards attributes of wines } \\
\hline Scent & Relevance of the scent: 1 not relevant, 4 very relevant & 2.429 & 0.991 & 1 & 4 \\
\hline Taste & Relevance of the taste: 1 not relevant, 6 very relevant & 3.228 & 1.004 & 1 & 5 \\
\hline Local & 1 if local origin of wine is important, 0 otherwise & 0.220 & 0.414 & 0 & 1 \\
\hline Price & Relevance of the price: 1 not relevant, 6 very relevant & 4.162 & 1.654 & 1 & 6 \\
\hline White wine & Relevance of the colour, white: 1 not relevant, 6 very relevant & 4.281 & 1.759 & 1 & 6 \\
\hline Rosè wine & Relevance of the colour, rosè: 1 not relevant, 6 very relevant & 2.216 & 1.937 & 1 & 6 \\
\hline \multicolumn{6}{|c|}{ W: Wine distribution channels } \\
\hline Large Retailers & 1 wine is manly purchased in large retailers, 0 elsewhere & 0.514 & 0.500 & 0 & 1 \\
\hline Web & 1 wine is manly purchased using internet, 0 elsewhere & 0.010 & 0.102 & 0 & 1 \\
\hline Wine shop & 1 wine is manly purchased in specialized wine shops, 0 elsewhere & 0.409 & 0.492 & 0 & 1 \\
\hline
\end{tabular}

The model parameters to be estimated on the basis of the sample observations are: $\alpha$, the intercept of the model while $\delta, \beta, \gamma$ e $\tau$ are the unknown coefficients. Estimated coefficients ( $\delta, \beta, \gamma$ e $\tau$ and $\tau$ parameters) indicate the direction and magnitude of the statistical associations between the explanatory variables (K X Z and $\mathrm{W}$ ) and the probability that the $i$-th respondent consumes a bottle of Sicilian wine.

Table 1 reports the explanatory variables used in the estimate while in the next paragraph the estimate result of the binary response model will be presented and discussed.

\section{Results}

A preliminary exploratory analysis of the collected data, may outline the profile of the ideal consumer of Sicilian wine. By analyzing the sample average values it is possible to evaluate the statistical association between the decision to consume wine and Sicilian wine and some socio-demographic variables of the respondent, such as age, level of education, income and gender (Table 2). About $84 \%$ of respondents declare that they consume wine, while the remaining $16 \%$ were teetotal. The ideal wine consumer can be depicted as follows: He is a male, characterized by an age, an income level and a degree of education slightly above the Italian average. In regards to the consumption of Sicilian wine, about $62 \%$ of the respondents declared to consume wine; $73 \%$ of the respondents in the South of Italy stated that they consume Sicilian wine, compared to the $58 \%$ in the North and the $44 \%$ in Central Italy (Table 3 ). The ideal consumer of Sicilian wine is a male and compared to the profile of the ideal wine consumer, he is slightly younger and with a higher degree of education and income level. In regards to the recorded level of consumption for the different types of wine, collected data show an annual consumption of about 50 litres per individual. Since this data excludes consumption of respondents under the age of 18 years, data reported in Table 1 seems to be consistent with that highlighted by (Dal Bianco et al., 2013) which reported a consumption of 47 litres per capita for individuals older than 15 years. Wine consumption appears to be highest in the North and in the South compared to what was recorded in the Central region. As for the "quality" of the wine consumed in Sicily only $58 \%$ of the total consumed wine appears to be wine characterized by the certification of origin (PDO or PGI), while this percentage rises to 61 and $66 \%$ for wine consumed respectively in the region of Northern and Central Italy (Table 4).

Table 5 shows the results of the estimate of Equation 1 obtained through the maximum likelihood estimator. In particular, following other empirical studies (Petrucci et al., 2014; Migliore et al., 2014; Zuorro et al., 2015), the estimated model coefficients, together with their standard errors and $p$-values, are reported. 
Francesco Caracciolo et al. / American Journal of Applied Sciences 2015, 12 (11): 794.801 DOI: 10.3844/ajassp.2015.794.801

Table 2. Socio-demographic characteristics of the sample

\begin{tabular}{|c|c|c|c|c|c|c|c|c|c|}
\hline \multirow[b]{2}{*}{ Variable } & \multirow[b]{2}{*}{ Description } & \multicolumn{2}{|c|}{ Total Sample } & \multicolumn{2}{|c|}{ Teetotaller } & \multicolumn{2}{|c|}{ Wine consumers } & \multicolumn{2}{|c|}{$\begin{array}{l}\text { Sicilian } \\
\text { wine consumers }\end{array}$} \\
\hline & & Mean & Std.dev & Mean & Std.dev & Mean & Std.dev & Mean & Std.dev \\
\hline Age & Age of the respondents & 45.62 & 13.69 & 33.27 & 12.08 & 48.01 & 12.67 & 47.14 & 12.27 \\
\hline Degree of education & $\begin{array}{l}0 \text { no education; } 1 \text { primary; } 2 \text { secondary; } \\
3 \text { High school; } 4 \text { Bachelor }\end{array}$ & 3.40 & 0.66 & 3.36 & 0.52 & 3.40 & 0.68 & 3.52 & 0.57 \\
\hline Level of income & $\begin{array}{l}\text { Household income: } 0 \max 15,000 \text { euros; } \\
1 \text { between } 15,000 \text { and } 30,000 \text { euros; } \\
2 \text { between } 30,000 \text { and } 50.000 \text { euro; } \\
3 \text { more than } 50,000 \text { euro }\end{array}$ & 1.31 & 0.80 & 1.08 & 0.73 & 1.36 & 0.81 & 1.48 & 0.81 \\
\hline Gender & 0 male; 1 female & 0.33 & 0.47 & 0.64 & 0.48 & 0.27 & 0.45 & 0.30 & 0.46 \\
\hline Relative frequency $(\%)$ & & 100.00 & & 16.18 & & 83.82 & & 62.27 & \\
\hline
\end{tabular}

Table 3. Relative frequency of wine consumers per geographic area

\begin{tabular}{|c|c|c|c|}
\hline & Penetration Index (wine) (a) \% & Penetration Index (Sicilia wine) (b) \% & $\mathrm{b} / \mathrm{a}$ ratio \\
\hline Southern Italy & 87 & 73 & 0.84 \\
\hline Northern Italy & 90 & 58 & 0.64 \\
\hline Central Italy & 72 & 44 & 0.61 \\
\hline Total & 87 & 62 & 0.71 \\
\hline
\end{tabular}

Table 4. Consumption of different typologies of wine (litres per month)

\begin{tabular}{|c|c|c|c|c|c|c|c|c|}
\hline & \multicolumn{2}{|c|}{ Southern } & \multicolumn{2}{|c|}{ Northern } & \multicolumn{2}{|c|}{ Central } & \multicolumn{2}{|l|}{ Italy } \\
\hline & Mean & std.dev & Mean & std.dev & Mean & std.dev & Mean & std.dev \\
\hline Common wine & 0.53 & 1.93 & 0.89 & 1.96 & 0.26 & 0.80 & 0.55 & 1.74 \\
\hline Bulk Wine & 1.39 & 3.82 & 1.01 & 2.22 & 0.61 & 1.58 & 1.10 & 3.04 \\
\hline Wine (PGI) & 1.00 & 1.61 & 1.19 & 1.88 & 0.48 & 1.12 & 0.92 & 1.60 \\
\hline Wine (PDO) & 1.63 & 1.92 & 1.82 & 2.20 & 1.17 & 1.86 & 1.56 & 1.99 \\
\hline Total wine & 4.55 & 4.19 & 4.91 & 3.81 & 2.51 & 2.60 & 4.14 & 3.87 \\
\hline
\end{tabular}

Table 5. Results of the estimate of the willingness to consume Sicilian wine

\begin{tabular}{|c|c|c|c|}
\hline & \multicolumn{3}{|c|}{ Sicilian Wine consumption } \\
\hline & Coeff. & t-stat & p-value \\
\hline \multicolumn{4}{|l|}{ Socio Demographic } \\
\hline$\delta$ : Age & -0.008 & -1.65 & 0.098 \\
\hline$\delta$ : Degree of education & 0.263 & 2.74 & 0.006 \\
\hline$\delta$ : Income & 0.304 & 3.89 & 0.000 \\
\hline$\delta$ : Gender & 0.253 & 2.02 & 0.044 \\
\hline$\delta$ : South & 1.157 & 8.45 & 0.000 \\
\hline \multicolumn{4}{|c|}{ Attitudes towards wine consumption } \\
\hline$\gamma:$ Between meals & -0.536 & -5.82 & 0.000 \\
\hline$\gamma:$ Restaurant & 0.087 & 2.00 & 0.046 \\
\hline$\gamma:$ Advertising & -0.120 & -2.83 & 0.005 \\
\hline$\gamma:$ Guides & 0.377 & 2.66 & 0.008 \\
\hline \multicolumn{4}{|c|}{ Preferences towards attributes of wines } \\
\hline$\beta:$ Scent & -0.072 & -1.25 & 0.212 \\
\hline$\beta$ : Taste & 0.062 & 1.06 & 0.289 \\
\hline$\beta$ : Local & -0.125 & -0.87 & 0.383 \\
\hline$\beta$ : Price & -0.054 & -1.44 & 0.149 \\
\hline$\beta$ : White & 0.072 & 2.10 & 0.036 \\
\hline$\beta$ : Rosè & -0.042 & -1.41 & 0.159 \\
\hline \multicolumn{4}{|c|}{ Wine distribution channels } \\
\hline$\tau$ : Large retailers & 0.401 & 3.18 & 0.001 \\
\hline$\tau:$ Web & 0.727 & 1.37 & 0.170 \\
\hline$\tau$ : Wine shops & 0.855 & 6.23 & 0.000 \\
\hline$\alpha:$ Constant & -0.540 & -0.91 & 0.363 \\
\hline
\end{tabular}

Notes: Number of observation $=953 ; \log$ likelihood $=-1726 ;$ Wald $\chi^{2}(90)=988.54 ;$ Pseudo $R^{2}=0.458$ 


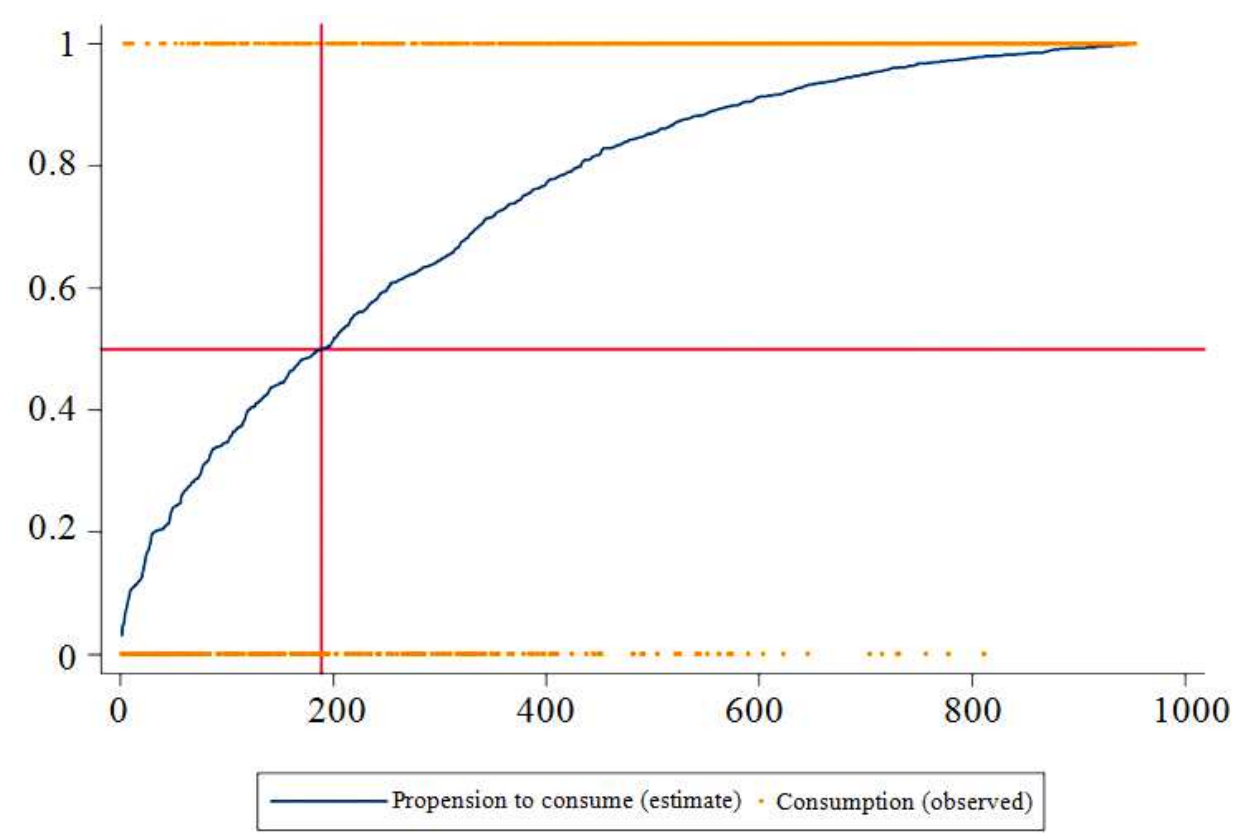

Fig. 1. Estimated function of willingness (or propensity) to consume Sicilian wine

Estimated model provided a reasonable fit to the data, with the majority of the parameters being statistically significative at $10 \%$ and a pseudo- $\mathrm{R}^{2}$ of 0.46 . Figure 1 illustrates the estimated willingness to consume Sicilian wine for the 953 respondents. The varies from 0 to 1 : Values close to zero indicate willingness to consume, while values close to 1 indicate high willingness. A detailed analysis of the graph highlights that only $19 \%$ of respondents (189 respondents out of 953) has a propensity to consume Sicilian wine lower than 0.5 . Only a small share of individuals is therefore less inclined to consume Sicilian wine. As discussed in the previous paragraph, the observed market penetration of the Sicilian wine is $71 \%$. The combination of those two figures may indicate that a group of respondents exists, around $10 \%$ of the sample, that although it is not currently a consumer it is likely to become one in the future. The characterization of this group becomes strategic for marketing purposes.

The following analysis goes in this direction and the coefficients reported in Table 5 may provide statistical evidence on the role of consumer characteristics on the propensity to consume Sicilian wine.

More in detail: Regarding the socio-demographic characteristics, the willingness to consume a Sicilian wine increases if:

Age is decreasing, the degree of education is higher, the income increases, you are female and if you are residing in the South of Italy.

Concerning the attitudes towards wine consumption, the propensity to consume Sicilian wine increases when:
Consumers prefer to consume wine during meals and in public places and when the choice of wine is influenced by the wine guides rather than the advertising.

Looking at the preferences of the respondents towards the attributes of wines, the willingness to consume Sicilian wine increases in consumers:

Who prefer white wine to red wine.

The last part of the analyses focused on the respondents' preferences according to the different wine distribution channels. Results show that the willingness to consume Sicilian wine increases:

In consumers used to purchasing wine in specialized shops (wine shops) and supermarkets rather than discount and hypermarkets.

This last finding would seem to confirm the result of a previous study on market penetration of certified wines highlighting the importance of wine shops as the favoured distribution channel especially for premium wines (D'Amico et al., 2014a).

\section{Discussion}

Sicilian wines are showing an increase of their relevance in the Italian and world market, fueled by the improvement in the quality of the supply mainly through the widespread of PDO and PGI and bottled wine 
productions (Crescimanno and Galati, 2014; Di Vita et al., $2013 b ; 2013 c)$. Thus, the analysis of the consumers preferences towards the Sicilian wines represents an interesting case study for both practitioners and researchers in the wine sector. Despite several authors widely arguing the main research approach to the consumption of regional brand wines and regionally denominated products (Rasmussen and Lockshin, 1999; Skuras and Dimara, 2004; Johnson and Bruwer, 2007) empirical studies on Sicilian wine are fairly limited and circumscribed to limited geographical areas (Caniglia et al., 2008; Lanfranchi et al., 2014c). Our Results confirmed the relevance of the Sicilian wine image and corroborated the important role played by Sicilian wine in the Italian wine market. Estimates provided evidence that income and habits to purchase at wine shops and the habit of drinking between meals significantly influence the willingness to consume Sicilian wines. Furthermore the sample willingness to consume the Sicilian wine increased for white wines and when the consumption takes place in public areas. Furthermore, it is important to underline that according to the estimates, "being price-conscious consumers" seems not to affect the consumption of Sicilian wine. This last result can be interpreted as evidence of the relative price "inelasticity" of the demand for Sicilian wine. The main implication of the findings obtained in this study consists in providing useful insights for wine managers and policy makers, in order to better address marketing and policy strategies targeting the potential consumers. Their profile characterization could be useful to further increase the market penetration of Sicilian wines. This study illustrated that the employed model was appropriated to characterize the empirical analysis carried out. However, since our sample was mainly collected within urban areas in Italy, samples from a wider geographic range will be necessary to further investigate the determinants of the preference for Sicilian wine. While it is very likely that studies conducted in rural areas do not yield substantively dissimilar results, the consumption pattern of Sicilian wine, in both terms of frequency and quantity of consumption could not be compared at all since distribution and availability of Sicilian wine may differ significantly. Furthermore our variables does not include (time-related) information on consumption frequencies and on the general characteristics of the household and each household member. In order to enhance understanding of the preferences towards Sicilia wine, research in foreign markets could extend our results.

\section{Conclusion}

This study analyze the determinants of the preference of Italian consumers towards Sicilian wines, by means of an econometric analysis performed on national sample of 953 consumers. A binary response model was employed to evaluate the most important variables (demographic profile, preference and attitudes) that influence the drinking wine choices of Italian consumers (Lanfranchi et al., 2014b; D'Amico et al., 2014b). Results emphasize that income and habits to purchase at wine shops and the habit to drink between meals significantly influence the willingness to consume Sicilian wines. Furthermore the propensity to consume the Sicilian wine increases for white wines and when the consumption takes placed in public spaces.

\section{Acknowledgement}

The authors would like to thank the four anonymous referees of this journal for providing useful comments on the earlier draft of this paper. We are indebted to the Agriculture Department of the Sicilian Regional Government for financial support.

\section{Funding Information}

This study is part of the research project "Analisi economico-gestionali della filiera vitivinicola in Sicilia e valorizzazione delle produzioni" financed by Regione Siciliana and directed by Professor Mario D'Amico.

\section{Author's Contributions}

This article is the result of the full and equal collaboration of all the authors.

\section{Ethics}

This article is original and contains unpublished material. The corresponding author confirms that all of other authors have read and approved the manuscript.

\section{References}

Bruwer, J. and R. Johnson, 2010. Place-based marketing and regional branding strategy perspectives in the California wine industry. J. Consumer Market., 27: 5-16. DOI: 10.1108/07363761011012903

Caniglia, E., M. D’Amico and I. Peri, 2008. An analysis of consumers' perception of the quality of the Etna DOC wine. New Medit., 7: 32-40.

Caracciolo, F., G. Cicia, T. Del Giudice, L. Cembalo and A. Krystallis et al., 2015. Human values and preferences for cleaner livestock production. J. Cleaner Product. DOI: $10.1016 /$ j.jclepro.2015.06.045

Caracciolo, F., L. Cembalo and E. Pomarici, 2013. The hedonic price for an Italian grape variety. Italian J. Food Sci., 25: 289-294. 
Cembalo, L., F. Caracciolo and E. Pomarici, 2014. Drinking cheaply: The demand for basic wine in Italy. Aus. J. Agric. Resources Econom., 58: 374-391. DOI: $10.1111 / 1467-8489.12059$

Crescimanno, M., A. Galati and T. Bal, 2014. The role of the economic crisis on the competitiveness of the agri-food sector in the main Mediterranean countries. Agric. Econom. Agriecon, 60: 49-64.

Crescimanno, M., G.B. Ficani and G. Guccione, 2002. The production and marketing of organic wine in Sicily. Brit. Food J., 104: 274-286. DOI: $10.1108 / 00070700210425714$

Crescimanno, M. and A. Galati, 2014. Competitiveness of Italian wines in the international market. Bulgarian J. Agric. Sci., 20: 12-22.

D'Amico, M., A. Coppola, G. Chinnici, G. Di Vita and G. Pappalardo, 2013. Agricultural systems in the European Union: An analysis of regional differences. New Medit., 4: 28-34.

D'Amico, M., G. Di Vita and G. Bracco, 2014a. Direct sale of agro-food product: The case of wine in Italy. Quality Access Success, 15: 247-253.

D’Amico, M., G. Di Vita, G. Chinnici, G. Pappalardo and B. Pecorino, 2014b. Short food supply chain and locally produced wines: Factors affecting consumer behaviour. Italian J. Food Sci., 26: 329-334.

Dal Bianco, A., V. Boatto and F. Caracciolo, 2013. Cultural convergences in world wine consumption. Revista de la Facultad de Ciencias AgrariasUNCuyo, 45: 219-231.

Dal Bianco, A., V. Boatto, F. Caracciolo and F. Santeramo, 2015. Tariffs and non-tariff frictions in the world wine trade. Eur. Rev. Agric. Econom. DOI: $10.1093 /$ erae/jbv008

Di Vita, G., M. D’Amico, G. La Via and E. Caniglia, 2013a. Quality perception of PDO extra-virgin olive oil: Which attributes most influence Italian consumer? Agric. Econom. Rev., 14: 46-58.

Di Vita, G., C. Bellia, G. Pappalardo and M. D'Amico, $2013 \mathrm{~b}$. The role of innovation and organization in small size wineries: The case of Malvasia delle Lipari PDO wine. Quality Access Success, 14: 107-112.

Di Vita, G., M. D'Amico and S. Bracco, 2013c. Economic performance of smallholders PDO wine grapes in Eastern Sicily. Quality Access Success, 14: 99-105.

Di Vita, G., G. Chinnici, G. Pappalardo, M. D’Amico and S. Bracco, 2014a. Standard output versus standard gross margin, a new paradigm in the EU farm economic typology: What are the implications for wine-grape growers? J. Wine Res., 25: 229-242. DOI: 10.1080/09571264.2014.959660

Di Vita, G., G. Chinnici and M. D'Amico, 2014b. Clustering attitudes and behaviours of Italian wine consumers. Quality Access Success, 15: 54-61.
Galati, A., M. Crescimanno, M. Rossi, D. Farruggia and S. Tinervia, 2014. The determinants affecting the internationalization of the Italian SMEs producing sparkling wines: An empirical study on the RBV of the firms. Int. J. Globalisat. Small Bus., 6: 100-118. DOI: 10.1504/IJGSB.2014.066463

Johnson, R. and J. Bruwer, 2007. Regional brand image and perceived wine quality: The consumer perspective. Int. J. Wine Bus. Res., 19: 276-297.

Lanfranchi, M., C. Giannetto, A. Zirilli and A. Alibrandi, 2014a. Analysis of the demand of wine in Sicily through ordinal logistic regression model. Quality Access Success, 15: 87-90.

Lanfranchi, M., C. Giannetto and A. Zirilli, 2014b. Analysis of demand determinants of high quality food products through the application of the cumulative proportional odds model. Applied Math. Sci., 8: 3297-3305. DOI: 10.12988/ams.2014.44278

Lanfranchi, M., C. Giannetto, M. D'Amico and G. Di Vita, 2014c. Analysis of demand determinants of fish products in Messina: An economic survey on the fish consumption. Quality Access Success, 15: 106-108.

Migliore, G., F. Caracciolo, A. Lombardi, G. Schifani and L. Cembalo, 2014. Farmers' participation in civic agriculture: The effect of social embeddedness. Culture, Agric. Food Environ., 36: 105-117.

Onofri, L., V. Boatto and A. Dal Bianco, 2015. Who likes it "sparkling"? An empirical analysis of Prosecco consumers' profile. Agric. Food Econom., 3: 1-15. DOI: 10.1186/s40100-014-0026-X

Orth, U.R., M. McGarry Wolf and T.H. Dodd, 2005. Dimensions of wine region equity and their impact on consumer preferences. J. Product Brand Manage., 14: 88-97. DOI: 10.1108/10610420510592563

Petrucci, E., L. Di Palma, R. Lavecchia and A. Zuorro, 2014. Treatment of diazo dye reactive green 19 by anodic oxidation on a boron-doped diamond electrode. J. Industrial Eng. Chem., 26: 116-121. DOI: $10.1016 /$ j.jiec.2014.11.022

Rasmussen, M. and L. Lockshin, 1999. Wine choice behaviour: The effect of regional branding. Int. J. Wine Market., 11: 36-46. DOI: 10.1108/eb008689

Roma, P., G. Di Martino and G. Perrone, 2013. What to show on the wine labels: A hedonic analysis of price drivers of Sicilian wines. Applied Econom., 45: 2765-2778. DOI: 10.1080/00036846.2012.678983

Skuras, D. and E. Dimara, 2004. Regional image and the consumption of regionally denominated products. Urban Studies, 41: 801-815. DOI: $10.1080 / 0042098042000194115$

Train, K.E., 2009. Discrete choice methods with simulation. Cambridge University Press.

Tudisca, S., A.M. Di Trapani, E. Donia, F. Sgroi and R. Testa, 2014. Entrepreneurial strategies of Etna wine farms. Int. J. Entrepreneurship Small Bus., 21: 155-164. DOI: 10.1504/IJESB.2014.059470 
Verneau, F., F. Caracciolo, A. Coppola and P. Lombardi, 2014. Consumer fears and familiarity of processed food. The value of information provided by the FTNS. Appetite, 73: 140-146.

DOI: $10.1016 /$ j.appet.2013.11.004
Zuorro, A., G. Maffei and R. Lavecchia, 2015. Reuse potential of artichoke (Cynara scolimus L.) waste for the recovery of phenolic compounds and bioenergy. J. Cleaner Product.

DOI: $10.1016 /$ j.jclepro.2015.06.011 